untreated. After induction of inflammation, we applied a protocol of forced tread mill running to increase biomechanical stress in half of the mice. Control mice with or without IMQ or DSS treatment did not run. We evaluated skin and gut disease severity clinically and by histology, and performed microCT scans, histologica and immunohistochemical analyses of the knees and the paws, to investigate eventual changes occurring in the joints.

Results: Clinical and histological assessment of the skin or gut confirmed successful induction of cutaneous and intestinal inflammation. The exercise protocol slightly affected the severity of the PsO- but not of the IBD-like disease in mice. In both models, disease was not confined to the target organs as systemic inflammation was demonstrated by trabecular bone loss, as indicated by microCT analyses, and by changes in spleen size. The exercise protocol did not appear to have an additional effect on these systemic disease manifestations, but it is associated with increased articular cartilage thickness and cellularity. Signs of mild joint inflammation were seen for both the IMQ and DSS models. Mild synovitis was triggered by skin and gut disease. At the entheseal level, immunohistochemica detection for CD45 +cells showed that forced exercise boosts inflammation in the presence of inflammation triggered at a distant site.

Conclusions: Induction of PsO- or IBD-like inflammation by local treatments of immune-privileged barrier tissues, such as skin and gut, also triggers a systemic response with inflammation-associated bone loss and discrete signs of joint disease. Forced running exercise increased the degree of enthesitis in this setting, providing new support for the hypothesis that biomechanical stress contributes to disease manifestations in PsA and other forms of spondyloarthritis.

Disclosure of Interest: None declared

DOI: 10.1136/annrheumdis-2018-eular.3218

\section{OP0273 \\ TRANSMEMBRANE TNF SIGNALLING THROUGH TNF-R INDUCES SPA-LIKE INFLAMMATION, WHEREAS SIGNALLINGTHROUGH TNF-RII IS CRUCIAL FOR NEW BONE FORMATION}

M. van Tok ${ }^{1}$, D. Pots ${ }^{1}$, I. Blijdorp ${ }^{1}$, M. Armaka ${ }^{2}$, G. Kollias ${ }^{2}$, M. van de Sande ${ }^{1}$ D. Baeten ${ }^{1}$, L. Van Duivenvoorde ${ }^{1} .{ }^{1}$ Clinical Immunology And Rheumatology, Amsterdam Medical Center, Amsterdam, Netherlands; ${ }^{2}$ Division of Immunology, Biomedical Sciences Research Center 'Alexander Fleming', Vari, Greece

Background: TNF can drive strictly distinct inflammatory pathologies depending on its expression form. Previously, we have shown that transmembrane (tm) TNF rather than soluble TNF contributes to key pathological features of spondyloarthritis ( $\mathrm{SpA}$ ), including new bone formation.

Objectives: Delineate the cellular and molecular mechanisms by which selective tmTNF overexpression leads to SpA-like pathology.

Methods: tmTNF tg mice (TgA86) ${ }^{2}$ were crossed with TNF-RI or TNF-RII knock out mice. Animals were followed for 100 days for clinical symptoms of arthritis and spondylitis development. Histology was performed at the end of the study on both peripheral and axial joints. Calvarial mouse fibroblasts were cultured in osteogenic conditions. Differentiation towards osteoblasts was analysed by alizarin red staining, alkaline phosphatase (ALP) staining as well as by qPCR for collagen type I, II, and X, ALP and RUNX2.

Results: Clinical arthritis, visualised by swelling and deformation of front- and hind paws, was observed in $100 \%$ of the $\operatorname{tmTNF}^{+/ N T}(>20)$ as well as in all

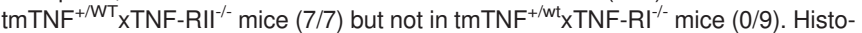
logically, peripheral synovitis, osteitis and enthesitis were observed in all tmTNF${ }^{+/}$

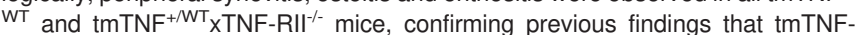
mediated synovitis requires the presence of the TNF-RI receptor. ${ }^{2}$ Similarly, hunch back formation and crinkled tails were observed in the tmTNF ${ }^{+/ W T}$ and the tmTNF ${ }^{+/ W T}$ xTNF-RII-/ mice but not in $\operatorname{tmTNF}^{+/ W T} \times \mathrm{TNF}^{-\mathrm{RI}}{ }^{-/-}$mice. Histology confirmed the presence of inflammatory cellular infiltrates at the edge of the intervertebral units in all tmTNF ${ }^{+/ W T}$ tg mice and all tmTNF ${ }^{+/ W T} \times T N F-R I^{-/-}$mice, but not in $\mathrm{tmTNF}^{+/ \mathrm{wt}} \times \mathrm{XNF}-\mathrm{Rl}^{-/-}$mice. Whereas these data indicate that TNF-RI is required for tmTNF-induced inflammation, it was striking that $50 \%(10 / 20)$ of the $\mathrm{tmTNF}^{+/}$

${ }^{\mathrm{WT}}$ versus none $(0 / 7)$ of the $\mathrm{tmTNF}^{+/ \mathrm{WT}}$ XTNF-RII ${ }^{-/-}$mice depicted clear histological signs of endochondral new bone formation. To test whether TNF-RII is involved in pathological new bone formation in this model, calvarial fibroblasts skulls from tmTNF $^{+/ W T}$, tmTNF $^{+/ W T} \times T N F-\mathrm{Rl}^{-/-}$, tmTNF $^{+/ W T} \times T N F-R I^{-/-}$or WT were differentiated with osteogenic medium with or without IL-17A. tmTNF overexpressing fibroblasts enhanced the osteogenic differentiation as observed by ALP and alizarin red staining and increased mRNA levels of Collagen type I and ALP compared to WT. This enhancement in osteogenesis was maintained in $\mathrm{TmTNF}^{+/ W T} \times T N F-\mathrm{Rl}^{-1}$ derived fibroblasts but abolished in $\mathrm{tmTNF}^{+/ \mathrm{WT}} \times \mathrm{XTNF}-\mathrm{R} \mathrm{II}^{-/-}$-derived fibroblasts.

Conclusions: The SpA-like phenotype in tmTNF tg mice is crucially dependent on TNF-RI to drive peripheral and axial inflammation, but TNF-RII signalling is required to drive the pathological new bone formation under inflammatory conditions.

\section{REFERENCES}

[1] Van Duivenvoorde L, van Tok M, Baeten D. Annals of the Rheumatic Diseases 2014;73:441-441

[2] Alexopoulou L, Pasparakis M, Kollias G. Eur J Immunol 1997:27 (10):2588-92.

Disclosure of Interest: M. van Tok: None declared, D. Pots: None declared, I. Blijdorp: None declared, M. Armaka Employee of: Biomedcode, G. Kollias Employee of: Biomedcode, M. van de Sande: None declared, D. Baeten Employee of: UCB Pharma, L. Van Duivenvoorde: None declared DOI: 10.1136/annrheumdis-2018-eular.2386

FRIDAY, 15 JUNE 2018

HPR Supporting self-management

\section{OP0274-HPR A FUNCTIONAL EXERCISE PROGRAM IMPROVES PAIN AND HEALTH RELATED QUALITY OF LIFE IN PATIENTS WITH FIBROMYALGIA: A RANDOMISEDCONTROLLED TRIAL}

G. Fernandes, F. Jennings, M. Cabral, R. Santos, J. Natour. Rheumatology Division, Universidade Federal de São Paulo, São Paulo, Brazil

Background: Fibromyalgia (FM) is a syndrome characterised mainly by chronic generalised pain that affects the physical fitness and functional capacity of patients. There is increasing evidence of the benefits of physical exercise in improving FM symptoms, making these interventions part of therapeutic arsenal. Objectives: To evaluate the effectiveness of a program of functional exercises in reducing pain, improving functional capacity, increasing muscle strength, improving flexibility, balance and quality of life of patients with FM.

Methods: It is a controlled and randomised study, with blind evaluator. A total of 82 female patients with FM were included, with age between 18 and 65 years randomised into two groups, intervention and control. The intervention group (FEG) performed functional exercise training for 45 min twice a week for 14 weeks. The control group (SEG) performed stretching exercises with the same duration and frequency. Evaluation instruments were: VAS - Visual Analogue Scale for pain assessment; FIQ- Fibromyalgia Impact Questionnaire, for assessing health-related quality of life; Time-up and go test for functional performance evaluation; 1RM, for evaluation of muscle strength; Bank of Welss, for the assessment of flexibility; Berg Balance Scale, to evaluate balance; and SF-36 to evaluate general quality of life. Also, the amount of analgesics used during the intervention period was assessed.

Results: 41 patients were randomised to the FEG and 41 patients to the SEG After intervention, the FEG presented a reduction in pain and an improvement in the quality of life related to the disease, which was statistically significant compared to SEG. Regarding general quality of life, functional capacity, muscle strength, flexibility and balance, there was no difference between the groups.

Conclusions: Functional exercise training proved to be effective in reducing pain and improving the health-related quality of life of patients with FM when compared to stretching exercises.

\section{REFERENCES:}

[1] Wolfe F, Clauw D, Fitzcharles MA, Goldenberg D, Katz RS, Mease P, et al. The American College of Rheumatology Preliminary Diagnostic Criteria for Fibromyalgia and Measurement of Symptom Severity. Arthritis Care Res 2010;62:600-10.

[2] Hauser W, Klose P, Langhorst J, et al. Efficacy of different types of aero bic exercise in fibromyalgia syndrome: A systematic review and meta-analysis of randomised controlled trials. Arthritis Res Ther 2010;12:R79.

[3] Burchardt CS. Multidisciplinary approaches for management of fibromyalgia. Curr Pharm Des 2006;12:59-66.

Disclosure of Interest: None declared

DOI: 10.1136/annrheumdis-2018-eular.1570 